\title{
Investigation of Blood Lactate Levels, Hearth Rates and Technical Performance of Hearing-Impaired Elite Male Greco-Roman Wrestlers
}

\author{
Ali Osman Kıvrak ${ }^{1}$, Sirin Pepe ${ }^{2}$ \\ ${ }^{1}$ Selcuk University, Faculty of Sports Sciences, Coaching Education Department, Konya, Turkey \\ ${ }^{2}$ Physical Education Teacher, Konya, Turkey \\ Correspondence: Ali Osman Kivrak, Selcuk University, Faculty of Sports Sciences, Coaching Education Department, \\ Konya, Turkey.
}

Received: March 14, 2019

Accepted: April 1, $2019 \quad$ Online Published: April 2, 2019

doi:10.11114/jets.v7i5.4139

URL: https://doi.org/10.11114/jets.v7i5.4139

\begin{abstract}
This study was conducted with hearing-impaired elite greco-roman wrestlers to determine the relationships and variations in heart rates (HR), blood lactate (La) levels and number of performances during the maximal effort and recovery periods. Voluntary 8 hearing-impaired elite male wrestlers with an average age of 21,75 $\pm 2,05$ years participated into present experiments. Resting heart rates of the athletes were determined before the maximal effort, blood samples were taken for lactate levels, athletes took warm up and stretching exercises for 15 minutes. For maximal effort, athletes performed hip-headlock throw technique for 2 minutes in 3 periods. Proper performances were counted and heart rates were measured in between the periods. To determine recovery characteristics of the athletes after maximal effort, HR and La levels were determined at $3^{\text {rd }}, 15^{\text {th }}$ and $30^{\text {th }}$ minutes after maximal effort.

Heart rate responds to hip-headlock throws at the end of the $1^{\text {st }}$ period were lower than the heart rates at the end of the $2^{\text {nd }}$ and $3^{\text {rd }}$ periods and heart rates at the end of the $2^{\text {nd }}$ period were lower than the heart rates at the end of the $3^{\text {rd }}$ period $(\mathrm{p}<0.05)$. Number of performances in the $1^{\text {st }}$ period was greater than the number of performances in the $2^{\text {nd }}$ and $3^{\text {rd }}$ periods and number of performances in the $2^{\text {nd }}$ period was greater than the number of performances in the $3^{\text {rd }}$ period $(\mathrm{p}<0.05)$. HR values increased and number of performances decreased with the progress of periods. There were significant differences in HR and number of performances of the periods $(\mathrm{p}<0.05)$.

HR and La reached to the maximum levels right after the end of wrestling game and a significant decrease was observed after the $3^{\text {rd }}$ minute of resting $(\mathrm{p}<0.00)$. Significant decreases continued at the $15^{\text {th }}$ and $30^{\text {th }}$ minutes of the resting as compared to the $3^{\text {rd }}$ minute $(\mathrm{p}<0.00)$. Blood lactate levels also reached to the maximum at the $3^{\text {rd }}$ minute of resting with the effort spend in the $3^{\text {rd }}$ period; then significant decrease was observed at the $15^{\text {th }}$ minute of resting $(\mathrm{p}<0.00)$ and significant decreases were also observed in blood lactate levels between the $15^{\text {th }}$ and $30^{\text {th }}$ minutes of resting $(\mathrm{p}<0.00)$.

It was concluded based on present findings that increasing heart rates negatively influenced number of performances. In other words, tiredness had negative effects on number of performances. Present findings also revealed that during the recovery period, lactate levels decreased quite slower than heart rates. In this sense, it was assumed that La level was the primary criterion of the recovery.
\end{abstract}

Keywords: wrestling, hearing-impaired, Lactate levels, hearth rates

\section{Introduction}

Hearing-impaired individual is defined as a person in need of special education because of difficulties experienced in acquisition of speaking, use of language and communications through partial or full loss of hearing ability (ÖEHY 2006). Disability is a status of a person incapable of the roles expected based on age, gender, social and cultural factors due to a disorder or handicap (Özer 2001). Entire behaviors are the outcomes of a learning process and such a process is harder and requires greater effort in hearing-impaired individuals as compared to hearing ones. Therefore, disabled individuals gain life experiences ending up with problems of compatibility in every phase of life (Özsoy et al., 1998). The disabilities of hearing-impaired individuals obtained from physical competence tests including speed, strength, agility, muscular endurance, power and cardiorespiratory endurance components indicated that these individuals need 
appropriate rehabilitation programs including proper motor activities and they should functionally be oriented to sports. In hearing-impaired individuals, learning disability and lack of motivation is experienced mostly because of communication problems. Such experiences then result in disability in perception of visual stimulants and coordination of movements (Çiftçi 2006). Sports fulfill a quite significant function for "integration" of disabled individuals with the healthy or the other disabled individuals which is the primary target of special education. In such environments, disabled individual observes the problems of the other disabled individuals and develops positive attitudes towards himself, his/her creativity is stimulated, feel of loneliness is minimized, he/she becomes sociable and has a chance of living a more meaningful life (Özer 2001).

Greco-roman wrestling is a modern style of wrestling in which wrestlers use their upper bodies to execute a variety of different plays and performed within the rules specified by International Wrestling Federation (FILA) (Kahraman 1989). This style of wrestling is a tough branch of sport. It requires high-intensity effort; is characterized with physical dominance of the athletes on each other; includes short periods of sub-maximal and maximal effort and resting periods. In Olympic Games, man and woman free-style and greco-roman style are available. Games are held in two periods of 3 min with 30 s resting period (Savranbaş1, 2011).

Wrestling is defined as a branch of sport with technical and intelligent moves requiring speed, strength, agility, flexibility, balance, muscular and cardiovascular endurance and coordination. Anaerobic energy system is dominantly used in wrestling (Akgün 1992, Gökdemir 2000, Kürkçü et al. 2007). Considering the entire duration of the game, aerobic system constitutes about $10 \%$-like small portion in wrestlers. The techniques in wrestling are short-duration exercises with a high amplitude. In this sense, aerobic capacity is low in wrestling. However, when the exercises during the preparation phases of the games into consideration, a high aerobic capacity can be mentioned (Ziyagil 1991 ).

Moving from the profiles of hearing-impaired national team wrestlers, this study was conducted to provide contributions to optimum training programs, loading and post-game recovery of the trainers and the athletes. Along with this general objective, heart rates and blood lactate levels, which are significant criteria designating the boundaries of aerobic and anaerobic capacity and training loading, were investigated and resultant values for the recovery were compared.

\section{Material and Method}

In present study, 8 elite hearing-impaired greco-roman wrestlers with international achievements and an average age of 21,75 $\pm 2,05$ years were included. Athlete resting heart rates (HR) and blood lactate (La) levels were measured. Athletes then took $15 \mathrm{~min}$ aerobic and free warm up and stretching exercises and full-rested for $5 \mathrm{~min}$. Following this period, each athlete applied hip-headlock throw technique at a maximal speed to a partner standing at starting position and unresisting for 2 minutes. This period was repeated three times for each athlete with 2 minutes of resting intervals. At the end of each period, athlete HR and successful number of performances (hip-headlock throws) applied were determined. At the end of three periods, HR and blood lactate levels were measured at $3^{\text {rd }}, 15^{\text {th }}$ and $30^{\text {th }}$ minutes.

\subsection{Heart Rates}

During the treatments, elastic breast bands were placed beneath the sternum at heart level of the athletes. Hearth rates were measured telemetrically with a monitor (polar-s610- s810) and recorded. Before the tests, the device was checked to prevent errors and improve reliability of the measurements.

\subsection{Number of Performances (Hip-Headlock Throws)}

In this study, the most common technique applied in greco-roman wrestling, "hip headlock throw" applied from standing position to the ground was preferred. It is an effective move in greco-roman style and it requires speed and trick of the opponent. Athlete body should be well-adapted to this technique for a successful performance. A successful performance includes full control of the partner's arm, locking the head of the opponent with the other arm and falling him down with the hip strike. Following full performance of the hip-headlock throw, athletes quickly stand up and continued the technique. During the implementations, number of performances was counted by a wrestling referee visually in sign language. Improper and incomplete performances were not counted.

\subsection{Blood Lactate Concentrations}

For lactate measurements, Accutrend Lactate/Accusport Portable Lactate Analyzer and Lactate Strips were used. By the help of AccuChek Softlix Lancet Needle, a little amount of (0.5-7 ml) blood was dripped on the Strip which was taken from the finger stick of the subject. It was concluded in 60 seconds.

\subsection{Statistical Analysis}

SPSS for Windows 16. software was used for statistical analyses of the experimental data. Repeated measures analysis of variance procedure was applied to compare measurement of the variables. Scheffe test was used for pairwise comparisons. Significance level was taken as 0.05 . 


\section{Results}

Physical characteristics of national team hearing-impaired greco-roman wrestlers are provided in Table 1; HR and number of performances at the end of the periods are provided in Table 2; comparison of recovery HR and La levels is provided in Table 3.

Table 1. Subject descriptive data (mean \pm SD)

\begin{tabular}{lccc}
\hline Parameters & N & X & SD \\
\hline Age (years) & 8 & 21,75 & 2,05 \\
Height (cm) & 8 & 174,75 & 5,31 \\
Weight (kg) & 8 & 83,81 & 19,21 \\
Grip strength (right hand, kg) & 8 & 39,24 & 9,67 \\
Grip strength (left hand, kg) & 8 & 38,06 & 9,95 \\
Blood fat percentage (BFP, \%) & 8 & 17,21 & 5,44 \\
\hline
\end{tabular}

In Table 1, arithmetic means and standard deviations were provided for age, height, weight, right and left hand grip strengths and body fat percentages.

Table 2. HR and number of performances at the end of the periods (Mean \pm SD)

\begin{tabular}{lllll}
\hline & N & Mean \pm SD & F & P \\
\hline HR, pulse/min $1^{\text {st }}$ Period & 8 & $185,0 \pm 13,6$ & & \\
HR, pulse/min 2 ${ }^{\text {nd }}$ Period & 8 & $188,37 \pm 13,8$ & 5,55 & 0.042 \\
HR, pulse/min $3^{\text {rd }}$ Period & 8 & $189,12 \pm 14,13$ & & \\
\hline Number of performances $1^{\text {st }}$ Period & 8 & $35,75 \pm 4,97$ & & \\
Number of performances $2^{\text {nd }}$ Period & 8 & $32,25 \pm 3,73$ & 32,57 & 0.000 \\
Number of performances $3^{\text {rd }}$ Period & 8 & $30,62 \pm 4,53$ & & \\
\hline
\end{tabular}

Variance analysis on measurements made, KAH, at the end of the second period was significantly higher than that at the end of first period $(\mathrm{p}<0.05)$. the number of games was significantly different in all periods $(\mathrm{p}<0.05)$.

Table 3. Comparison of recovery HR and La levels

\begin{tabular}{lllll}
\hline Durations & N & F & P \\
\hline HR, pulse/min Resting & 8 & $60,5 \pm 5,42$ & & \\
HR, pulse/min End of $3^{\text {rd }}$ Periods & 8 & $189,12 \pm 14,13$ & & 0.000 \\
HR, pulse/min + Resting $3^{\text {rd }}$ min & 8 & $126,37 \pm 8,76$ & 182.32 & \\
HR, pulse/min + Resting $15^{\text {th }}$ min & 8 & $77,75 \pm 28,57$ & & \\
HR, pulse/min + Resting $30^{\text {th }}$ min & 8 & $60,75 \pm 13,0$ & \\
\hline La, $m M$ Resting & 8 & $1,53 \pm 0,73$ & & \\
La, $m M$ Resting End of $3^{\text {rd }}$ Period & 8 & $16.01 \pm 2,08$ & & \\
La, $m M$ Resting $+3^{\text {rd }}$ min & 8 & $14,05 \pm 1.05$ & 117,97 & \\
La, $m M$ Resting $+15^{\text {th }}$ min & 8 & $10,40 \pm 2,45$ & & \\
La, $m M$ Resting $+30^{\text {th }}$ min & 8 & $7,90 \pm 1,08$ & & \\
\hline
\end{tabular}

The greatest HR was observed at the end of the $3^{\text {rd }}$ period of hip-headlock throw performance and the greatest decline was observed after the $3^{\text {rd }}$ minute of recovery. The decrease in HR at recovery was found to be significant $(\mathrm{p}<0.05)$. While high lactate levels were observed at the end of hip-headlock throw performance, the decreases at the $15^{\text {th }}$ and $30^{\text {th }}$ minutes of recovery were found to be significant $(\mathrm{p}<0.05)$.

\section{Discussion and Conclusion}

In this study, maximal efforts and heart rates of elite hearing-impaired wrestlers were investigated and changes and relationships between heart rates (HR) and blood lactate (La) levels of number of performance and recovery period were put forth. 
Athlete average age of the present study was determined as $21,75 \pm 2,05$ years. Çamçakallı et al (2014) in a study reported average athlete age as $21,6, \pm 2,5$ years. Jelena et al (2009) reported average athlete age as $20,64 \pm 3,36$ years; Yoon (2002) reported average age of Korean wrestlers as 23 years; Bahman et al (2009) reported average age of the elite free-style wrestlers of Iran as 19,8 $\pm 0,9$ years. Present average age of wrestlers was complying with the average ages of the previous studies.

Average athlete height of the present study was $174,75 \pm 5,31 \mathrm{~cm}$. Thomas et al (2008) in a study reported average height of the wrestlers as 174,9 $\pm 10,9 \mathrm{~cm}$; Jelena et al (2009) reported average height of wrestlers as $175,41 \pm 7,42 \mathrm{~cm}$. Present average height of the wrestlers was also complying with the average heights reported in previous studies.

Average athlete body weight of the present study was $83,81 \pm 19,21 \mathrm{~kg}$. Mirzaei and Akbarnejad (2008) reported average body weight of the wrestlers as $81,5 \pm 20,2 \mathrm{~kg}$. Present body weights were complying with the values of the previous studies.

In present study conducted with 8 voluntary elite wrestlers, average resting HR of the wrestlers was $60,50 \pm 5,42$ pulse/min, right hand grip strength was $39,24 \pm 9,67 \mathrm{~kg}$, left hand grip strength was $38,06 \pm 9,95 \mathrm{~kg}$ and body fat percentage was $17,21 \pm 5,44 \%$.

Parallel outcomes were observed for heart rates and number of performances. Heart rate responds to hip-headlock throws at the end of the $1^{\text {st }}$ period were lower than the heart rates at the end of the $2^{\text {nd }}$ and $3^{\text {rd }}$ periods, heart rate after performance of the technique at the end of the $2^{\text {nd }}$ period was lower than the heart rate at the end of the $3^{\text {rd }}$ period. Number of performances in the $1^{\text {st }}$ period was greater than the number of performances in the $2^{\text {nd }}$ and $3^{\text {rd }}$ periods; number of performances in the $2^{\text {nd }}$ period was greater than the number of performances in the $3^{\text {rd }}$ period. HR values increased and number of performances decreased with the progress of the periods. Increasing HRs indicated that wrestlers were getting tired with the progress of the periods. Such a tiredness then resulted in decreasing number of performances.

Savranbaşı (2011) reported significantly different heart rates and number of performances of free-style wrestlers in three periods during the game $(\mathrm{p}<0.05)$. Heart rates increased and number of performances decreased at the end of each period. Present findings comply with those earlier ones.

Heart rates reached to the maximum level at the end of wrestling game, but exhibited a significant decrease at the $3^{\text {rd }}$ minute of resting and significantly decreased at $15^{\text {th }}$ and $30^{\text {th }}$ minutes of the resting as compared to the $3^{\text {rd }}$ minute $(\mathrm{p}<0.00)$.

Blood lactate levels also reached to the maximum with the effort spend in the $3^{\text {rd }}$ period; then significant decreases were observed in blood lactate levels at the $3^{\text {rd }}, 15^{\text {th }}$ and $30^{\text {th }}$ minutes of resting $(\mathrm{p}<0.00)$. Increasing blood lactate levels indicated a tiredness of the wrestlers. Resultant tiredness then resulted in decreasing number of performances. In present study, the recovery in lactate levels was slower as compared to heart rates, the recovery was faster during the initial 15 minutes, then slowed down later on.

Menzies et al. (2010) reported a fast decrease in lactate levels until the $16^{\text {th }}$ minute of the recovery and slowed down decreases later on. Menzies et al. (2010) also reported similar findings with the present study. Ghorbani et al. (2015) reported significant increases in lactate levels during the game, but significant decreases were observed in lactate levels at the $10^{\text {th }}, 15^{\text {th }}$ and $20^{\text {th }}$ minutes of the recovery. Present findings on lactate levels comply with those earlier ones.

During the official events, athletes may have to wrestle in 15 -minute intervals. The lactate level at the $15^{\text {th }}$ and $30^{\text {th }}$ minutes of the recovery was respectively measured as 10,40 and $7,09 \mathrm{mM}$. In this case, a second game at the $15^{\text {th }}$ minute of the recovery will create a significant disadvantage for the performance of the athlete.

It is already known that wrestling requires actions of instant and explosive strength, anaerobic energy metabolisms are actively used in games, and aerobic system plays a significant role in maintenance of wrestler activities throughout the game and rapid recovery in resting periods.

Greater aerobic capacity allows wrestlers to recover faster between the games or in resting periods, thus has great contributions to athlete performance. The athletes with a well aerobic capacity recovers faster after the game. Wrestlers compete in several games during the tournaments. An athlete with a high aerobic capacity then recovers better until the next game.

Aerobic performance is as much effective as anaerobic performance in winning the games. The athletes targeting upper most level of success should develop both their anaerobic and aerobic capacities. At the end of the game, while a fast recovery is observed in heart rates, slower recovery is observed in lactate levels. Therefore, instead of heart rates, blood lactate levels should be taken into consideration to determine resting levels of the athletes. It was concluded that as well as heart rates, blood lactate levels should also be monitored while determining resting durations of the wrestlers in between loadings in trainings. 


\section{References}

Akgün, N. (1992). Exercise Physiology. $4^{\text {th }}$ Edition, Volume 1. İzmir, Ege University Press, 60-201-203 (in Turkish).

Bahman, M., David, G. C., Farhad, R., \& Mehrzad, M. (2009). Physiological profile of elite İranian junior freestyle wrestlers. Journal of Strength and Conditioning Research, 23(8), 2339-2344. https://doi.org/10.1519/JSC.0b013e3181bb7350

Çamçakallı, A., Pepe, H., \& Altın, M. (2014). Aerobic and Anaerobic Power profile of elite Turkish Greco-Roman Wrestlers, Niğde University Journal of Physical Training and Sport Sciences, 8(3), Nigde.

Çiftçi, D. (2006). Response of Hearing-Impaired $1^{\text {st }}$ Grade Primary School and $8^{\text {th }}$ Grade Secondary School Students to 8-Week Training Program. Institute of Social Science, Physical Training and Sports Department. Master's Thesis, Sakarya: Sakarya University, (in Turkish).

Ghorbani, S., Mohebbi, H., Safarimosavi, S., \& Ghasemikaram, M. (2015). The effect of different recovery methods on blood lactate removal in wrestlers. J Sports Med. Phys. Fitness. Apr; 55(4), 273-279.

Gökdemir, K. (2000). Scientific Principles of Wrestling Trainings. Ankara, Poyraz Offset, (in Turkish).

Jelena, Z. P. G., Otto, F. B., \& Nikola, G. G. (2009). Maximal anaerobic power test in athletes of different sports disciplines. Journal of Strength and Conditioning Research, 23(3), 751-755. https://doi.org/10.1519/JSC.0b013e3181a07a9a

Kahraman, A. (1989). Turkish Wrestling Until Republic. Volume: 1, Ankara, Ministry of Culture Publications, (in Turkish).

Kürkçü, R., Pepe, H., Hazar, H., \& Hazar, F. (2007). Assessment of One Year Hearth, Circulatory and Anaerobic Development of 14-16 Years Old Wrestler, S.Ü Journal of Physical Training and Sports, 9(3), 16-23, Konya, (in Turkish).

Menzies, P., Menzies, C., McIntyre, L., Paterson, P., Wilson, J., \& Kemi, O. J. (2010). Blood lactate clearance during active recovery after an intense running bout depends on the intensity of the active recovery. $J$ Sports Sci., 28, 975-982. https://doi.org/10.1080/02640414.2010.481721

Mirzaei, B., \& Akbarnejad, A. (2008). A skill profile of elite Iranian Greco-Roman Wrestlers. World journal of sport sciences (WJSS), l(1).

ÖEHY. (2006). Regulations for Special Training Services, 31.05.2006 dated and 26184 numbered Official Gazette. (in Turkish).

Özer, D. S. (2001). Physical Training and Sports for Handicapped, $1^{\text {st }}$ Issue, Nobel Press, Ankara, (in Turkish).

Özsoy, Y., Özyürek, M., \& Eripek, S. (1998). Introduction to Special Training: Children in Need of Special Education. Ankara: Karatepe, (in Turkish).

Savranbaşı, R. (2011). Investigation of the Relations among Blood Lactate Level, Hearth Rate and Technical Performance of Elite Male Free-Style Wrestler, Journal of Sports Refereeing, 46, 87-96, (in Turkish).

Thomas, W. B., Douglas, B. S., Matthew, S. O., Aric, J. V., \& Stephan, J. R. (2008). Seasonal changes of body mass, body composition and muscular performance in collegiate wrestlers. International Journal of Sports Physiology and Performance, 3, 176-184. https://doi.org/10.1123/ijspp.3.2.176

Yoon, J. (2002). Physiological profiles of elite senior wrestlers. Sports Med, 32(4), 225-233. https://doi.org/10.2165/00007256-200232040-00002

Ziyagil, M. A. (1991). Investigation of the Relations among Anthropometric Characteristics, Biomotor Capabilities and Success of Wrestler. M.Ü. Institute of Health Sciences, Physical Training and Sports Department, Ph.D. Thesis, (in Turkish).

\section{Copyrights}

Copyright for this article is retained by the author(s), with first publication rights granted to the journal.

This is an open-access article distributed under the terms and conditions of the Creative Commons Attribution license which permits unrestricted use, distribution, and reproduction in any medium, provided the original work is properly cited. 